\title{
Severe acute respiratory distress syndrome in COVID-19 infected pregnancy: a case report
}

\author{
Nagashree Undinti ${ }^{1 *}$, Charumathi $\mathbf{R}^{1}$, Rama Narasimhan ${ }^{2}$, Neetu Mariam Alex ${ }^{2}$
}

\begin{abstract}
${ }^{1}$ Department of Obstetrics and Gynecology, Apollo Women's Hospital, Chennai, Tamil Nadu, India
${ }^{2}$ Department of Medicine, Apollo Hospitals, Chennai, Tamil Nadu, India
\end{abstract}

Received: 10 October 2020

Revised: 16 November 2020

Accepted: 02 December 2020

\section{*Correspondence:}

Dr. Nagashree Undinti,

E-mail: dr.nagashree@yahoo.com

Copyright: (C) the author(s), publisher and licensee Medip Academy. This is an open-access article distributed under the terms of the Creative Commons Attribution Non-Commercial License, which permits unrestricted non-commercial use, distribution, and reproduction in any medium, provided the original work is properly cited.

\section{ABSTRACT}

Corona virus 2019 is an emerging disease with a rapid increase in cases and deaths. Limited data is available about its progress and consequences in pregnancy. We present clinical challenges and potential strategies for optimal materno fetal surveillance by a case report on how we successfully managed a COVID -19 infected elderly primigravida with twin gestation and severe acute respiratory distress syndrome.

Keywords: COVID-19, Maternal fetal surveillance, Chest CT, Mechanical ventilation

\section{INTRODUCTION}

The beta corona viruses are single stranded, nonsegmented, enveloped RNA viruses which usually cause illness ranging in severity from common cold to severe respiratory illness and death. ${ }^{1}$ Data suggest incubation period ranging from 2-14 days and average of 5 days. Other manifestations are fever, sore throat, drycough, myalgia, headache, dyspnea, conjunctivitis, diarrhoea, loss of taste and smell, a rash on skin, or discolouration of fingers or toes. It is transmitted by close person to person contact, droplets and perhaps also surface contact contamination and through aerosol generating procedures-endotracheal intubation, manual ventilation before intubation, open suctioning etc. In some cases, feco oral transmission also is reported. ${ }^{2}$ (Ahmed et al, Grasssia et al, Wen et al).

\section{CASE REPORT}

Mrs. X, an elderly primigravida (48 yrs) at 28 weeks gestation/dichorionicdiamniotic twin gestation (DCDA)/ intra cytoplacmic sperm injection (ICSI) pregnancy/ gestational diabetes mellitus (GDM) on insulin/ gestational hypertension/hypothyroid with prophylactic cervical encirclage. Cervical encirclage was done at 13 weeks prophylactically in view of precious pregnancy, ICSI and twin gestation. She came to emergency with severe breathlessness and admitted on 2nd June 2020 as she was diagnosed COVID positive with breathlessness for the past 2 days. No history of cough, sick contact or recent travel. She presented with complaints of severe breathlessness, inability to lie in supine position. She was tachypnoeic, afebrile and hypoxic (temperature- $98.6 \mathrm{~F}$, respiratory rate; $30 / \mathrm{min}, \mathrm{SpO} 2-88 \%$ at room air, Pulse rate- $88 / \mathrm{min}$, blood pressure- $110 / 60 \mathrm{mmHg}$ ) requiring 3 liters of oxygen via nasal prongs. She was admitted to COVID isolation ward. She had bilateral lung crepitations Basic investigations like blood works were notable for anemia, leukocytosis with relative lymphopenia, and mild thrombocytosis. (Haemoglobin$10.4 \mathrm{mg} / \mathrm{dl}$, WBC count $21,000 / \mathrm{mm}^{3}$ with $5 \%$ of lymphocytes, platelet count $-4,98,000 / \mathrm{mm}^{3}$ ) chest $\mathrm{X}$ ray with double lead shield done revealing heterogenous opacities in bilateral middle and lower zones (Figure 1). ECG and ECHO done, which were normal. She was started on LMWH (Clexane $0.4 \mathrm{ml} \mathrm{s} / \mathrm{c}$ od, antivirals lopinavir/ritonavir, IV steroids and IV Inj. Meropenem 1 
gm tds. Inflammatory markers were serially monitored as shown below. Rest of the biomarkers; obstetric ultrasound and doppler were normal. She was monitored with CTG and urine albumin twice a day.

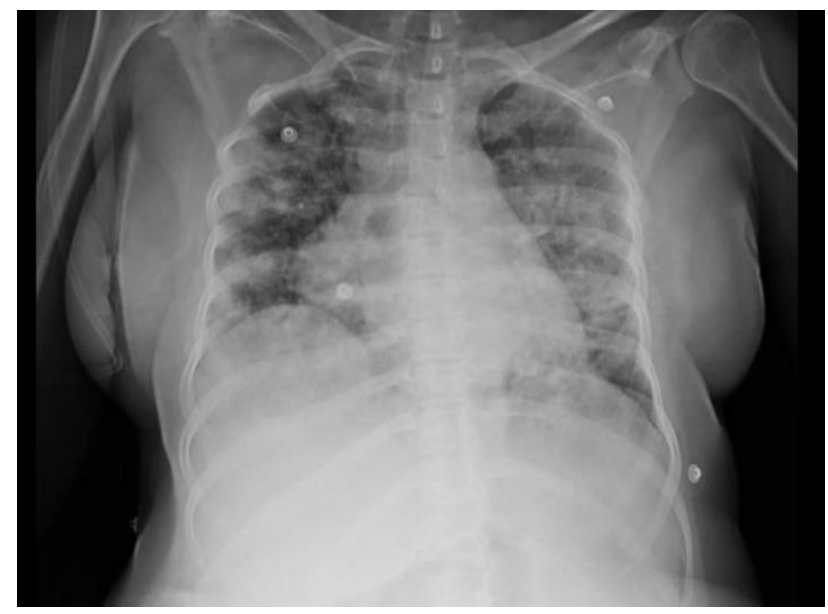

Figure 1: Chest X-Ray.

Her arterial blood gas analysis showed high anion gap metabolic acidosis and elevated serum ketone levels. Adequate IV hydration and IV insulin infusion were started. She was managed by high flow nasal canula (HFNC) and noninvasive ventilation initially. Antibiotics were escalated to POLY B 7.5 lakhs IU and Tigecycline $150 \mathrm{mg}$ IV bd. On day 5 of symptom onset, she was intubated and started on volume control mechanical ventilation in view of worsening hypoxia and increased work of breathing. High vaginal swab cultures grew Candida auris and she had fluctuating haemodynamics, started her on Caspofungin $50 \mathrm{mg}$ IV od. The CTG was none reassuring with decreased variability indicating fetal distress-so a multi-disciplinarypanel discussion between the obstetrician, internist and intensivist was conducted and a decision to terminate pregnancy was taken. This decision was taken taking into consideration both mother and babies. The mother could be given the best care if the babies would be delivered and could be life saving for the mother. It was an IVF pregnancy, very precious indeed. Detailed counselling regarding severity of pneumonia, imminent kidney failure, high mortality risk, need for prolonged ICU stay for the mother and NICU stay for preterm babies was explained and proceeded with Emergency LSCS on 6.6.2020 after the intubation.

She delivered twin girls of weights- $1.3 \mathrm{~kg}$ and another $630 \mathrm{gms}$ by LSCS. Apgar score at $1 \mathrm{~min}$ was 7 and 5 for twin 1 and twin 2 respectively. Both of them were intubated and then shifted to NICU for ventilator support in view of extreme prematurity and for further management. Both the babies were tested negative for COVID-19. Circlage stitch was removed. During hospital stay, the mother had 2 episodes of sepsis with multiple secondary bacterial infections for which she was treated. New onset Burdholderia cepacian seen on blood cultures and bacteremia seen with urine culture showing MDR klebsiella - and this was managed with antibiotics like meropenem, tigecycline, poly $\mathrm{B}$, ceftazidime. She required ionotrope support along with prolonged mechanical ventilation. She underwent tracheostomy on day 20 to facilitate prolonged ventilator support.

Repeat CT scan chest was suggestive of COVID related changes fibrotic bands in both lungs, diffuse ground glass opacities, interlobar septal thickening nodular lesions, small patch sub pleural consolidation in both lower lobes (Figure 2).

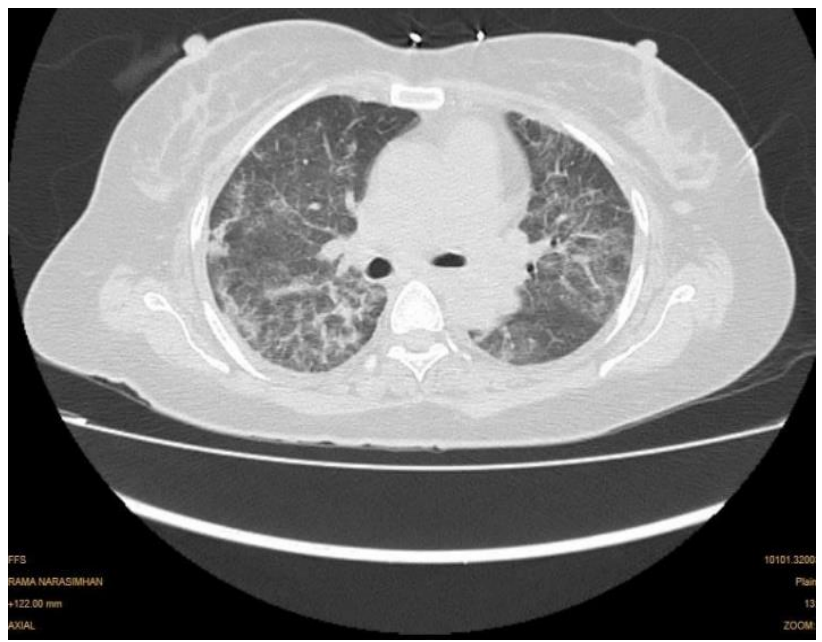

Figure 2: Chest CT scan.

She had left foot drop -L5-S1 showing radiculopathy which was treated symptomatically.

She eventually recovered with steroids and other supportive measures, her oxygenation improved and tracheostomy closure done on 35th day. She was kept on dexamethasone after tracheostomy closure. Mother was discharged on 45th day of ICU stay with a plan to continue oral steroids and taper over the next few weeks. At the time of discharge -first twin was $1.9 \mathrm{~kg}$; second twin was $1.5 \mathrm{~kg}$ both were able to feed well. The first twin was discharged on $46^{\text {th }}$ day of NICU stay. The second twin was discharged on around $66^{\text {th }}$ day of NICU stay. Mother and both the babies have been discharged and are doing well.

\section{DISCUSSION}

The physiological changes in pregnancy makes women more vulnerable to COVID-19 infection and causes rapid deterioration in the condition. ${ }^{3}$ NAT -Nucleic acid amplification technique is the gold standard for diagnosing viral pneumonia caused by SARS COV-2 infection. Real time reverse transcriptase PCR is used for NAT. Specimens can be obtained through upper respiratory tract (oronasopharynx), lower respiratory tract (bronchial extracts, trachea, alveolar lavage/lung tissue biopsy. 


\section{Diagnosis}

\section{Biochemical indicators of prognosis}

RTPCR (real time reverse transcription polymerase chain reaction) is used for NAT.

Patients with SARS-COV 2 infection may develop hypoxemia which may not have any apparent symptoms and depending on the severity of the illness they may develop, multiple organ dysfunction with micro emboli.

Elevated procalcitonin has a great significance for clinical diagnosis of sepsis. In case of elevated ALT; AST, LDH, Phosphocreatine kinase and myoglobin it indicates patient suffering from multiple organ dysfunction. Elevated troponin and those with lower absolute lymphocyte count indicate poor prognosis. Elevated NLR number-Neutrophil to Lymphocyte ratio is an independent risk factor affecting the occurrence of severe illness. $^{4}$

Serial monitoring of CRP, with level above 100, IL-6; IL 10, and CD8+T lymphocyte levelsand NLR can help assess risk of worsening condition of Covid-19 patients5.

\section{Imaging}

\section{Chest X ray}

Ground glass (GGO) pattern is the most common finding in COVID -19 infections. It may start as unifocal lesion mostly in the inferior lobe of right lung but may present as multifocal, bilateral and peripheral lesions in later stages of the disease. ${ }^{6}$

\section{CT-chest}

CT with high resolution to lungs is preferred. Mostly bilateral multiple lesions are observed; usually at the periphery of lungs, under pleura, lower lungs. They could be small patches/large ground glass opacities, irregular fan shaped/flaky. Crazy paving- defined as presence of thickened interlobular and intralobular lines in combination with a ground glass pattern. In advanced cases, there could be bronchial vascular thickening /sub pleural bands. Another common finding in the areas of ground glass is traction bronchiectasis. The easiest way to score the severity is by visual assessment. Pleural effusion, pericardial effusion, lymphadenopathy, cavitation, CT halo sign and pneumothorax are possible findings seen with disease progression.

\section{Ultrasound}

It is mostly focused on heart and lungs for COVID-19 patients, severe patients present with multiple organ failure. It is used to rule out the presence of deep venous thrombosis and arterial embolism in peripheral vessels of extremities. COVID inflammation tends to cause microemboli. Progressive increase in D dimer is an early warning sign of disease aggravation and DIC occurrence. Therefore, patients are prone to DVT and PE, so as a routine practice anticoagulant are started.

So therapeutic anti coagulation was started in our patient. Laboratory parameters may show progressive increase in D-dimer value is which is an early warning sign of the onset of the procoagulant DIC. 30\% show shortened PT/APTT value. They might show normal/slightly increased platelet count. Fibrinogen could be increased in COVID patients which decreases in later stages of disease in patients with DIC with consumptive hypocoagulability. ${ }^{7-11}$

\section{Obstetric management in COVID-19 patients with lung symptoms}

Decisions about the use of steroids for fetal lung maturity in preterm cases should be made in consultation with Infectious department and materno- fetal medicine specialists. At the time of admission due to COVID pneumonitis, our patient was already started on IV steroids. It was advised that 2 different steroids cannot be given to the same patient and it would have anyways served the purpose of lung maturity.

Individualised decisions regarding delivery should be considered based on gestational age of the fetus and should be made in conjunction with neonatologist. ${ }^{12}$ Decision regarding Magnesium sulphate administration for fetal neuro protection before 32 weeks gestation has to proceed as per standard indications. This provides an additional benefit of bronchodilation in the setting of bronchospasm after intubation. In our case, it was an emergency due to fetal distress; we didn't have enough time to start the Magnesium sulphate infusion. Furthermore, our patient was already in respiratory failure-it would have further caused respiratory depression.

Restriction of IV fluids to $125 \mathrm{ml} /$ hour is done. Delayed cord clamping and immediate skin to skin maternal contact should be avoided. Consistent with previous studies, clinical symptoms from 33 neonates with or at risk of COVID-19 were mild and outcomes were favourable. ${ }^{13-15}$ No evidence for vertical transmission so far noted in late pregnancies. ${ }^{16}$

According to a study on 116 COVID-19 cases in pregnancy-12.5\% had spontaneous abortion,6.1\% had preterm birth. ${ }^{17}$ There is no evidence of transmission through breast feeding in the literature so far, however it should be done taking precautions as proper hand hygiene and wearing a mask while handling the baby.

Emerging evidence suggests that anti-viral agents like Remdesivir may be effective against SARS-COV-2, but Oseltamivir -neuraminidase inhibitors have no proven benefit. ${ }^{18,19}$ Continuous positive airway pressure are not 
recommended for managing acute hypoxemic respiratory failure due to their increased chances for urgent transition to invasive ventilation. ${ }^{20}$ Rapid sequence endotracheal intubation should be performed as per routine with consideration of smaller size of tube due to edematous and narrowed airway in pregnant patients. Prone ventilation is found significantly improve oxygenation in ARDS, its feasibility and safety in pregnancy have been documented. $^{21,22}$ In cases where mechanical ventilators might not be sufficient to support adequate oxygenation ECMO (extra corporeal membrane oxygenation) maybe tried.

\section{CONCLUSION}

Principles of management include early isolation, aggressive infection control procedures, O2 therapy, avoidance of fluid overload, empirical antibiotics, lab testing for virus and coinfection, fetal monitoring, early mechanical ventilation for progressive respiratory failure, individualized delivery planning, team multidisciplinary approach.

\section{ACKNOWLEDGMENTS}

We thank The Management of Apollo hospitals, Dr. Venkatachalam (Director of Medical Services, Apollo Hospitals), Dr. Rachna Misra (Medical Superintendent of Apollo Womens Hospital, Chennai), ICU Consultants of Apollo Hospital, NICU Consultants of Apollo Womens Hospital for their valuable support all throughout. We express our sincere thanks and gratitude to all the Nurses, Technicians, Housekeeping staff for rendering their valuable services.

\section{Funding: No funding sources}

Conflict of interest: None declared

Ethical approval: Not required

\section{REFERENCES}

1. Su S, Wong G, Shi W, Liu J, Lai AC, Zhou J, et al. Epidemiology, genetic recombination, and pathogenesis of coronaviruses. Tren Microbiol. 2016;24(6):490-502.

2. Hui DS, Zumla A. Severe acute respiratory syndrome: historical, epidemiologic, and clinical features. Infect Disea Clin. 2019;33(4):869-89.

3. Schnettler WT, Al Ahwel Y, Suhag A. Severe acute respiratory distress syndrome in coronavirus disease 2019-infected pregnancy: obstetric and intensive care considerations. Am J Obstet Gynecol MFM. 2020:100120.

4. Liu J, Liu Y, Xiang P, Pu L, Xiong H, Li C, et al. Neutrophil-to-lymphocyte ratio predicts severe illness patients with 2019 novel coronavirus in the early stage. Med Rxiv Epub ahead of print. 2020;12.

5. Liu J, Li S, Liu J, Liang B, Wang X, Wang H, et al. Longitudinal characteristics of lymphocyte responses and cytokine profiles in the peripheral blood of
SARS-CoV-2 infected patients. E Bio Medicine. 2020:102763.

6. Zhou S, Wang Y, Zhu T, Xia L. CT features of coronavirus disease 2019 (COVID-19) pneumonia in 62 patients in Wuhan, China. Am J Roentgenol. 2020;214(6):1287-94.

7. Chen N, Zhou M, Dong X, Qu J, Gong F, Han Y, et al. Epidemiological and clinical characteristics of 99 cases of 2019 novel coronavirus pneumonia in Wuhan, China: a descriptive study. Lancet. 2020;395(10223):507-13.

8. Wang D, Hu B, Hu C, Zhu F, Liu X, Zhang J, et al. Clinical characteristics of 138 hospitalized patients with 2019 novel coronavirus-infected pneumonia in Wuhan, China. J Am Medic Assoc. 2020;323(11):1061-9.

9. Guan WJ, Ni ZY, Hu Y, Liang WH, Ou CQ, He JX, Liu L, Shan H, Lei CL, Hui DS, Du B. Clinical characteristics of 2019 novel coronavirus infection in China. MedRxiv. 2020.

10. Huang C, Wang Y, Li X, Ren L, Zhao J, Hu Y, et al. Clinical features of patients infected with 2019 novel coronavirus in Wuhan, China. Lancet. 2020;395(10223):497-506.

11. Tang N, Li D, Wang X, Sun Z. Abnormal coagulation parameters are associated with poor prognosis in patients with novel coronavirus pneumonia. J Thrombos Haemost. 2020;18(4):844-7.

12. Lapinsky SE. Management of acute respiratory failure in pregnancy. Sem Respirat Critic Care Medic. 2017;38(2):201-7.

13. Zhu H, Wang L, Fang C, Peng S, Zhang L, Chang G, et al. Clinical analysis of 10 neonates born to mothers with 2019-nCoV pneumonia. Translat Pediat. 2020;9(1):51.

14. Chen H, Guo J, Wang C, Luo F, Yu X, Zhang W, et al. Clinical characteristics and intrauterine vertical transmission potential of COVID-19 infection in nine pregnant women: a retrospective review of medical records. Lancet. 2020;395(10226):809-15.

15. Wei M, Yuan J, Liu Y, Fu T, Yu X, Zhang ZJ. Novel coronavirus infection in hospitalized infants under 1 year of age in China. $\mathbf{J}$ Am Medic Assoc. 2020;323(13):1313-4.

16. Chen H, Guo J, Wang C, Luo F, Yu X, Zhang W, et al. Clinical characteristics and intrauterine vertical transmission potential of COVID-19 infection in nine pregnant women: a retrospective review of medical records. Lancet. 2020;395(10226):809-15.

17. Guan WJ, Ni ZY, Hu Y, Liang WH, Ou CQ, He JX, et al. Clinical characteristics of coronavirus disease 2019 in China. N Eng J Medic. 2020;382(18):170820.

18. Wang M, Cao R, Zhang L, Yang X, Liu J, Xu M, et al. Remdesivir and chloroquine effectively inhibit the recently emerged novel coronavirus (2019-nCoV) in vitro. Cell Res. 2020;30(3):269-71.

19. Li H, Wang YM, Xu JY, Cao B. Potential antiviral therapeutics for 2019 Novel Coronavirus. Chin J Tubercul Res Diseas. 2020;43:E002. 
20. Arabi YM, Fowler R, Hayden FG. Critical care management of adults with community-acquired severe respiratory viral infection. Intens Care Medic. 2020;46(2):315-28.

21. Dennis AT, Hardy L, Leeton L. The prone position in healthy pregnant women and in women with preeclampsia-a pilot study. Bio Med Cent Pregnan Childbir. 2018;18(1):445.

22. Akatsuka M, Tatsumi H, Yama N, Masuda Y. Therapeutic evaluation of computed tomography findings for efficacy of prone ventilation in acute respiratory distress syndrome patients with abdominal surgery. J Critic Care Med. 2020;6(1):3240 .

Cite this article as: Undinti N, Charumathi R, Narasimhan R, Alex NM. Severe acute respiratory distress syndrome in COVID-19 infected pregnancy: a case report. Int $\mathrm{J}$ Reprod Contracept Obstet Gynecol 2021;10:368-72. 